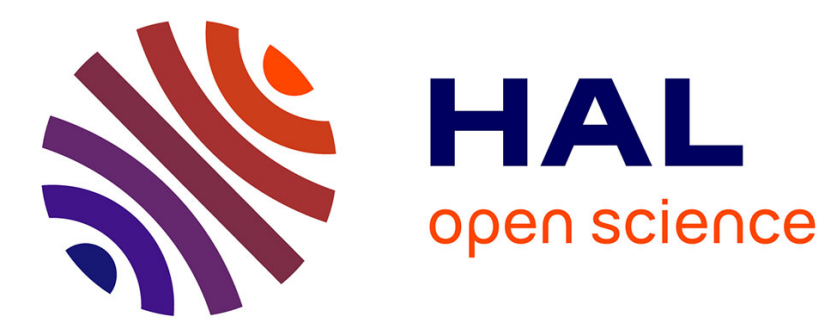

\title{
Developmental programming of natural killer and innate lymphoid cells
}

\author{
Christian A. J. Vosshenrich, James Di Santo
}

\section{To cite this version:}

Christian A. J. Vosshenrich, James Di Santo. Developmental programming of natural killer and innate lymphoid cells. Current Opinion in Immunology, 2013, 10.1016/j.coi.2013.02.002 . hal-01406501

\section{HAL Id: hal-01406501 \\ https://hal.science/hal-01406501}

Submitted on 7 Dec 2016

HAL is a multi-disciplinary open access archive for the deposit and dissemination of scientific research documents, whether they are published or not. The documents may come from teaching and research institutions in France or abroad, or from public or private research centers.
L'archive ouverte pluridisciplinaire HAL, est destinée au dépôt et à la diffusion de documents scientifiques de niveau recherche, publiés ou non, émanant des établissements d'enseignement et de recherche français ou étrangers, des laboratoires publics ou privés. 


\title{
Developmental Programming of Natural Killer and Innate Lymphoid Cells
}

Christian A.J. Vosshenrich ${ }^{1,2}$ and James P. Di Santo ${ }^{1,2}$

1'Unité d'Immunité Innée, Institut Pasteur, 25 rue du Docteur Roux, 75724 Paris, France 2INSERM U668, 75724 Paris, France

Corresponding authors:

james.di-santo@pasteur.fr

christian.vosshenrich@pasteur.fr

Short title: NK and ILC Developmental Pathways

\section{Highlights:}

ILCs include NK cells, nuocytes/NH cells, LTi cells and NKp46+ IL-22+ cells.

ILC rapidly produce cytokines (IL-5, $-13,-17 \mathrm{~A},-22$, IFN- $\gamma$ ) required for immunity to infection.

Transcription factors program ILC differentiation from lymphoid precursors.

ILC and Th responses are coordinated during innate and adaptive immunity.

\begin{abstract}
In recent years we have witnessed a blooming interest in innate lymphoid cell (ILC) biology thanks to the discovery of novel lineages of ILC that are phenotypically and functionally distinct from NK cells. While the importance of these novel ILC subsets as essential functional components of the early immune responses are now clearly established, many questions remain as to how early ILC developmental fates are determined and how specific effector functions associated with individual ILC subsets are achieved. As the founding member of the ILC family, properties of NK cells have defining attributes that characterize this group of innate effectors. Analysing their developmental rules may provide clues to principles that guide ILC development in general.
\end{abstract}




\section{Introduction}

ILC represent an expanding family of innate effector cells that have critical roles in the generation and maintenance of immunity, especially at mucosal surfaces. Natural Killer (NK) cells can be considered as the founding member of the ILC family, having immunological characteristics that include a lymphoid developmental origin, absence of clonally rearranging antigen receptors, and an activation profile that includes T-bet (Tbx21)-regulated prompt cytokine production (IFN- $\gamma$ ) but generally does not result in long-lasting immunological memory. We know much about the molecular determinants that guide NK cell development and generate these potent innate effector cells in both mouse and man (reviewed in [1-3]). The second ILC family member identified was the Lymphoid Tissue-inducer (LTi) cell that expresses the retinoic acid receptor-related orphan receptor $\gamma \mathrm{t}(\mathrm{ROR} \gamma \mathrm{t})$ and has a determinant role in lymphoid tissue formation during fetal and adult life. In adult mice, ROR $\gamma$ t-expressing LTi cells can also promptly produce IL-17 and IL-22 following activation with cytokines such as IL-1 $\beta$ and IL-23 suggesting that LTi cells have additional roles in immune defense (reviewed in [4]). More recently, other IL-22-producing $\mathrm{ROR} \gamma \mathrm{t}^{+}$ILC that express natural cytotoxicity receptors have been described in mucosal tissues from mice and man (reviewed in [5]). Finally, novel ILC subsets that have the capacity to produce high levels of the Th2 cytokines IL-5 and IL-13 were discovered and variably named natural helper cells, nuocytes or innate helper cells (reviewed in [6]). All of these different ILC subsets have common characteristics of lymphoid morphology, independence from the recombinase machinery, and a common developmental dependence for the transcriptional repressor Id2 and for $\gamma_{c}$ cytokines (reviewed in [7]). Recently, a standardized nomenclature was proposed for describing these functionally different ILC subsets: group 1 ILC include NK and other ILC that produce IFN $\gamma$ and are dependent on T-bet for their development and function; group 2 ILC comprise ILC that produce type 2 cytokines (IL-4, IL-5, IL-9 and IL13) and are dependent on Gata3 and ROR $\alpha$ for their development and function; and group 3 ILC subtypes that produce IL-17 and/or IL-22 and depend on ROR $\gamma$ t for their

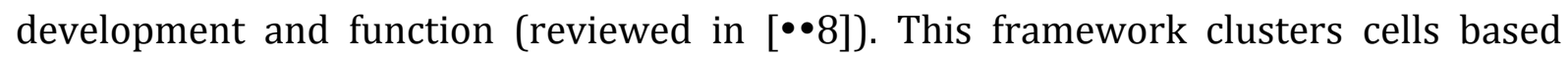
primarily on functional characteristics but also on signature transcription factors that drive their cytokine production. Still, functional plasticity is characterized by 
modifications in cytokine secretion profiles that can result from changes in transcription factor expression. As such, an inter-conversion between different ILC subsets may occur during immune responses or following ILC activation. Nevertheless, this ILC nomenclature may be useful to help understand and define the general principles that guide the development of ILC subsets from hematopoietic precursors.

While these new ILC subsets have generated considerable interest and excitement within the scientific community, remarkable advances in our understanding of the development and functional differentiation of NK cells have as well been recently reported. In this review, we will discuss our current knowledge on the development of NK cells from early hematopoietic precursors in the mouse, focusing on the transcription factors that orchestrate this process and discuss how these developmental pathways may also provide insights in to the developmental biology of other ILC subsets.

\section{A Refined Model for Bone Marrow NK cell Development in the mouse}

During hematopoiesis hematopoietic stem cells give rise to progressively more restricted precursor populations that generate lymphoid restricted common lymphoid progenitor (CLP) as well as precursors with restricted myeloid potential (CMP). In the mouse, CLP possess precursor potential for T, B, and NK cell at the single cell level [9], and can give rise to ILC2 at the population $[\bullet \cdot 10,11]$ and single cell level (Klein Wolterink and Di Santo, submitted). CLP are lineage marker (Lin') negative and express of low levels of c-Kit (CD117), Sca1 (Ly6A/E), IL7R $\alpha$ (CD127) and Flk2/Flt3 (CD135). A decade ago, we reported identification of the earliest murine NK cell committed precursor (NKP) residing within a Lin- population expressing the IL2/15R $\beta$ chain (CD122)[12]. The developmental potential of this population was limited to NK cells, but only gave rise to NK cells in vitro with a frequency of one in ten, indicating that the NKP subset was not functionally homogeneous. The fact that only $10 \%$ of phenotypically defined NKP had true NK precursor potential meant that mutations strongly affecting NKP development could go unnoticed, while normal NKP numbers might still be present in mice lacking almost all phenotypically defined NKPs. As such, it was difficult to reach definitive conclusions regarding factors that influence NKP homeostasis. While the identification of NKP was an important advance, the pathway between CLP and NKP was still poorly defined. 
Recently, two reports have further refined the phenotypic definition of NKP and also provided evidence for an additional NK committed precursor populations that is upstream of NKP. Fathman et al. used in vitro assays and in vivo adoptive transfer experiments to identify NKP $[\bullet 13]$. They found that all NK cell potential resided in a Lin$\mathrm{CD} 27^{+} \mathrm{CD} 244^{+}$fraction that included several $\mathrm{CD} 127^{+}$cell subsets. As expected, this included CD135 ${ }^{+}$CLP, but also included two additional NK cell restricted subsets. Both of these subsets lacked CD135, but they differentially expressed CD122: the CD122subset was designated a pre-NKP, while the second $\mathrm{CD} 122^{+}$subset likely corresponds to a refined definition of our previously identified NKP subset, termed refined NKP (rNKP), that also was shown to contain $\mathrm{CD} 122^{+} \mathrm{CD} 127^{+}$cells [12-14]. Together, this report would suggest a model where the transition from CLP to NKP that involves sequential down-regulation of CD135, up-regulation of CD122, followed by down-regulation of CD127 (Figure 1). This refined model of early NK cell development should provide a means to further dissect the transcriptional program that accompanies NK cell specification and commitment in the mouse. Along these lines, analysis of Ets-1 mutant mice demonstrated a clear defect in pre-NKP and rNKP cells $[\bullet \bullet 15]$, while analysis of Rag2 $x \gamma_{c}$ DKO mice showed a decrease in the CD122 ${ }^{+} \mathrm{CD} 127^{+}$NKP subset but not in its immediate CD122-CD127+ precursor (Brauner, Vosshenrich and Di Santo; unpublished results).

In a second report, Carotta et al. used an Id2 reporter mouse to identify early NK cell precursor cells in adult bone marrow. They also identified NK cell potential (using in vitro assays on OP9 stromal cells) amongst Lin-CD127+ cell populations that lacked

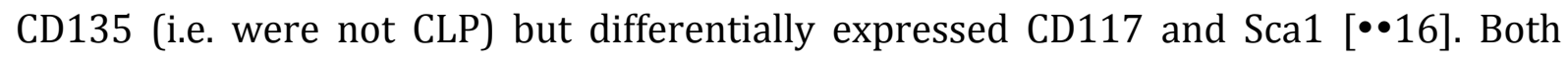
populations lacked CD122 expression but expressed low levels of NKG2D, previously identified on a subset of NKP $[14, \bullet \bullet 16]$ and were therefore different from previously identified NKP; these cells were referred to as pre-pro NK cells and likely correspond to the pre-NKP described by Fathman [16]. Interestingly, these pre-pro NK cells also appear to phenotypically overlap with a recently identified CD $127^{+}$Sca $1^{\text {hi }}$ ILC2 precursor population that also expresses CD25 and T1/ST2 [17]. Whether the pre-pro NK cell populations described by Carotta et al. harbors ILC2 potential or whether the putative ILC2 precursor described by Halim et al. also contains NK cell potential has not been studied $[\bullet \bullet 16, \bullet \bullet 17]$. Potentially, these populations might represent an interface between ILC1 and ILC2 development. 
Figure 1

\section{Transcriptional Regulation of NK Cell Development}

\section{General considerations}

During the lineage restriction of hematopoietic precursor cells undergo dramatic alterations at both proteomic and transcriptomic levels. Alternative lineage-potentials are progressively restrained until desired cell fates are completed. These changes occur within a dynamic cellular context that varies with respect to topography (cell niche, microenvironmental positioning) as well as activation state (resting/steady-state versus infectious/inflammatory milieu). Transcription factor repertoires consist of lineagedetermining factors ('master regulators') that need to be co-expressed with transcriptional modifiers (such as NFKB, or Foxo1) to orchestrate transcriptional programs through cooperative binding with other lineage-determining transcription factors to regulatory promoters/enhancers and activate transcription via recruitment of chromatin remodeling proteins $[18,19]$. Epigenetic regulation represents an additional layer that controls TF access to their binding sites. The loci of master regulators like Pax5 or Ebf1 have been shown to carry both activating and repressive marks in HSC before lineage-specification takes place, that resolve into either positive marks upon specification along the corresponding lineage or into repressive marks upon specification into a different lineage $[20,21]$. In a similar fashion, bivalent epigenetic marks are found as well in more differentiated Th cells that may help explain the observed plasticity in Th subset differentiation [••22].

\section{Transcription factors driving generation of NK cell precursors (NKP)}

While NKP represent a lymphoid precursor stage that is distinct from $\mathrm{T}$ and $\mathrm{B}$ cell precursors and has demonstrated NK cell potential, it is not yet shown whether NKP lack potential for other ILC lineages. Similarly, pre-NKP or pre-pro NKP have likewise been shown to give rise to NK cells, but their capacity to generate other ILC subsets has not been excluded. Nevertheless, several TF have been identified that are critical for the development of multiple ILC subsets (including NK cells) but do not overtly affect T or B cell precursor activity. The prime example is that of the transcriptional repressor Id2 
that acts (like all Id proteins) to counteract E box TF (E2A, E2-2, HEB) activity. In the absence of Id2, very few NK cells develop and residual cells display maturation defects [23,24]. Importantly, ILC2 and ILC3 subsets (LTi cells, IL-22-producing NKp46+ cells) are equally dependent on Id2 activity for their development $[7,8]$. This would place Id2 at an early stage of ILC development, potentially involved in the generation of a common ILC precursor. While earlier analysis of NKP in Id2\% mice suggested a normal development of NKP [24], a further analysis of rNKP as well as pre-NKP/pre-pro NKP cells in these mice should also be performed. This would provide interesting information on the role of Id2 repressor activity in early ILC precursor development.

Thymocyte selection-associated high mobility group box (Tox) is a second example of a TF that predominantly affects ILC but not T and B cell commitment. Tox deficiency ablates NK cell development and in addition, strongly reduces generation of group ILC3, especially LTi cells, resulting in decreased lymph node and Peyer's patch formation [25]. Whether Tox is required for the generation of ILC2 or other ILC3 subsets (IL-22-producing NKp46+ cells) is not known. Moreover, the mechanism by which Tox promotes the development of NK and LTi cells is poorly understood and the analysis of pre-NKP/pre-pro NKP cells and rNKP in Tox $/$ - mice has not been reported.

Several TF affect NK cell generation through a reduction in multiple lymphoid precursor populations; these may include CLP or their downstream committed progenitors for the B, T, NK and possibly other ILC lineages. This group of TF includes Ikaros and Gfi1 that compromise CLP and more restricted lymphoid precursors ([26,27], Klein Wolterink and Di Santo; unpublished). Another TF that may fall into this category is Ets-1 that has roles in B and T cell lineage development, and also in NK commitment,

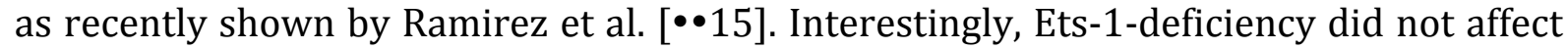
CLP numbers but resulted in the reduction of NK cell committed pre-NKP and rNKP populations that ultimately translated to a 5-10 fold reduction in mature NK cells $[\bullet \bullet 15]$. Ets-1 targets in mature NK cells include Idb2 (coding for Id2), Tbx21 (T-bet) and Il2rb (CD122), although these targets were not confirmed in NKP. Low levels of Ets-1 are

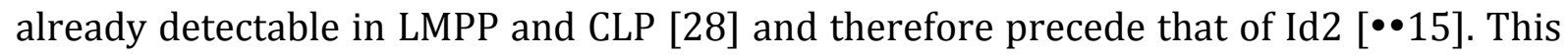
observation suggests that Ets-1 might be upstream of Id2 in the NK lineage-defining program. Still, the NK cell deficiency in Id2\% mice is stronger than that of Ets $-1 \%$ mice that might be due to the fact that Id2 levels are reduced but not ablated in absence of Ets-1. Alternatively, other Ets-family members may compensate in the absence of Ets-1 
to maintain Id2 levels. Since Ets-1 controls CD122 mRNA expression in NK cells $[\bullet \bullet 15]$ and regulates CD127 expression in peripheral T cells [29], Ets-1 may have additional roles in the development of other ILC groups.

\section{Transcription factors driving immature NK cells development from NKP}

Beyond the TF that determine the initial steps in NKP and (possibly) other ILC precursor generation, several TF have been identified that play critical roles in the development of 'immature' NK cells in the bone marrow and other tissues. Immature NK cells can be defined as CD3-CD122 ${ }^{+} \mathrm{NK} 1.1^{+} \mathrm{DX} 5^{-}$and are thought to represent a transient developmental intermediate that can further differentiate giving rise to mature NK cells that circulate in the blood and are detected throughout the organism.

One critical TF require for iNK generation is Nfil3/E4bp4, a transcriptional activator/repressor that was initially identified as protein binding the ATF site in the adenovirus E4 promoter [30]. While Nfil3 is strongly expressed in mature NK cells and their precursors, it is not an NK cell-specific TF, and is expressed in T, B and dendritic cell (DC) subsets, where it regulates production of Th2 cytokines IL-5, IL-10, IL-13 in T cells, IL-12 production from macrophages and TLR-3 induced IL-12 production from $\mathrm{CD} 8 \alpha^{+} \mathrm{cDC}$ and is involved in the regulation of Ig germ-line epsilon expression affecting subsequent class switch to IgE (reviewed in [31]). In the absence of Nfil3, NK cell homeostasis is strongly reduced and NK cell differentiation is blocked at the iNK cell stage $[\bullet \cdot 32-34]$. While downstream targets of Nfil3 are not clearly defined, residual levels of Gata3 and Id2 were reduced in Nfil3-deficient lymphoid precursors, suggesting that Nfil3 may regulate these TFs. Whether Nfil3 KO mice have defects in the generation of other ILC subsets has not been reported, although preliminary data indicated normal LN development [35] and presence of IL-22+ NKp46+ intestinal ILC3 (Xu, Serafini and Di Santo, unpublished) ruling out a role for Nfil3 in controlling differentiation of all ILC3 subsets. These observations would further suggest that Nfil3 does not regulate Id2 in a global fashion but would rather play a more selective role in development of NK cells and perhaps other IFN- $\gamma$-producing ILC1.

The TF Tbx21 (encoding T-bet) was initially described as a 'master regulator' of Th1 differentiation and also shown to control IFN- $\gamma$ production in various T cell subsets. The initial analysis of NK cell differentiation in T-bet KO mice found several defects [36], 
although most appeared related to the homeostasis of mature NK cells that may be related to regulation of receptors for S1P5 [37]. Tbx21 is a member of a larger family of TF that also includes the broadly expressed Eomesodermin [38]. Functional redundancy between T-box TF has been demonstrated in several cell types and T-bet/Eomes are coexpressed in $\mathrm{CD}^{+} \mathrm{T}$ cells where they have overlapping/redundant roles $[39,40]$. Recently, an interesting study of the specific versus redundant role of T-bet and Eomes

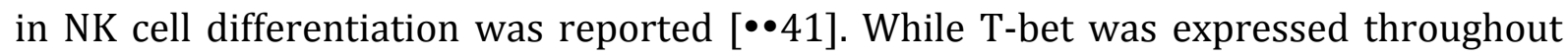
NK cell development (in iNK and mNK in newborn and adult mice), Eomes expression was more restricted and was clearly absent in DX5- iNK cells that could be found throughout the body but were conspicuously enriched in the liver [ $\bullet 41]$. Previous studies have characterized these DX5- hepatic NK cells and using adoptive transfer experiments showed that they could give rise to functionally mature NK cells (with upregulation of DX5 and acquisition of MHC class I-specific Ly49 receptors and effector functions) [42]. In the absence of Eomes, NK cell development was blocked at the DX5iNK cell stage, clearly indicating a role for Eomes in terminal NK cell maturation. The residual Eomes- iNK cells expressed T-bet and the combined deletion of T-bet and Eomes ablated development of all NK cells beyond the NKP stage [•41]. Further analysis of Tbx21\% mice demonstrated a defect in the generation of iNK cells, placing Tbet as a critical regulator of the NKP -> iNK transition (Figure 2). The transcriptional targets of T-bet at this stage are not known but may include the NK cell activating receptors Ncr1 and Cd161 (encoding NKp46 and NK1.1, respectively) [•*41] that may further complicate the unambiguous identification of T-bet-deficient iNK cells.

The TF Gata3 has multiple stage-dependent roles in T-cell development and has also been shown to control multiple aspects of NK cell subset differentiation and more recently, ILC2 differentiation ([43-••47], RKW submitted). Gata3 is a zinc-finger TF that binds a consensus $(\mathrm{A} / \mathrm{T}) \mathrm{GATA}(\mathrm{A} / \mathrm{G})$ motif and can deliver activating or repressive transcriptional signals. The critical targets of Gata3 in early lymphoid precursors are not fully defined. In immature thymocytes, Gata3 binds hundreds of distinct loci for which the functional implications are not clear $[\bullet \bullet 22]$. Interestingly, one predominant Gata3 target is the retinoic acid receptor ROR $\alpha$ that has multiple roles in hematopoietic and non-hematopoietic lineages. The similar loss of ILC2 in Gata3 and ROR $\alpha$ deficiencies $[\bullet 10, \bullet 17, \bullet 46, \bullet 47]$ suggest that these two TF operate in a sequential fashion (Gata3 $->\operatorname{ROR} \alpha)$. 
The effects of Gata3 ablation on NK cell development include an ablation of hepatic and $\mathrm{CD} 127^{+}$thymic NK cells and a defect in BM and splenic NK cell maturation; the latter involves a reduction in CD11b and CD43 expression on mature NK cells and a decrease in their IFN- $\gamma$ producing capacity $[43,44]$. The loss of IFN- $\gamma$ was unexpected and indicated that Gata3 could regulate T-bet in NK cells [43], although a role for Gata3mediated control of Eomes expression can not be ruled out (see below). The selective impact of Gata3 deletion on thymic versus BM NK cell homeostasis suggests that these two developmental pathways are distinct. Concerning thymic NK cell development, we hypothesize that Gata3 is upregulated in lymphoid precursors that enter the thymic microenvironment; this may involve a Notch-dependent signal, although this does not appear to be essential [•48]. Gata3-expressing lymphoid intrathymic precursors primarily generate T cells, but can give rise to NK cells and ILC2 $[\bullet \bullet 10,44,49]$. Gata3 ${ }^{+}$NK cells that develop within the thymus differ phenotypically and functionally from mature splenic NK cells (higher IFN- $\gamma$, CD16- few Ly49 receptors); these different attributes may be transiently imposed by the thymic microenvironment. Along these lines, adoptive transfer of thymic NK cells to $\mathrm{Rag} / \gamma_{\mathrm{c}}$ recipients allows for their further maturation with acquisition of Ly49 receptor repertoires and loss of CD127 (Vosshenrich, Di Santo; unpublished results).

Concerning hepatic NK cells, it is tempting to speculate that functions of Gata3, Eomes and T-bet may again be intertwined. In the absence of T-bet, hepatic NK cells, especially the immature DX5- subset, are decreased in number. The DX5+ subset is also affected but possibly 'rescued' due to Eomes expression [•41] either through local generation of $\mathrm{DX}^{+} \mathrm{NK}$ cells in the liver or from influx of $\mathrm{DX} 5^{+} \mathrm{NK}$ cells from the bone marrow. In contrast, Gata3 deficiency strongly reduces all hepatic NK cell subsets. While the mechanism behind this defect is not understood, one possibility is that Gata3 controls not only T-bet but also Eomes expression in hepatic NK cells. Further experiments are required to validate this hypothesis.

\section{Transcription factors driving NK cell maturation}

Several TF have been found to impact on the differentiation at later stages of NK cell differentiation. Of these, Eomes appears as a critical factor required for completion of NK cell maturation following DX5 acquisition (stage 4; Figure 1). Interestingly, NK 
cells lacking Eomes, T-bet or bearing temporal deletions in both genes retained significant functional capacities $[\bullet 41]$ indicating that Eomes/T-bet-independent regulation of $\mathrm{NK}$ cell cytotoxicity and cytokine production. In contrast, inducible deletion of Eomes in $\mathrm{DX5}^{+}$mature NK cells resulted in the appearance of DX5- NK cells that co-expressed TRAIL; this demonstrates that Eomes is actively required in order to maintain the mature NK cell phenotype. Moreover, these DX5- NK cells preferentially accumulated in the liver, suggesting that this tissue provides an environment that favors homeostasis of this NK cell subset.

Helios, another zinc-finger $\mathrm{TF}$ and member of the Ikaros family is abundantly expressed in immature CD11b- NK cells [50]. Helios over-expression has been associated with hyper-activated mature NK cells mice carrying 'Noe' mutations in the Ncr1 locus that ablate NKp46 cell surface expression [50]. The proposed link between the absence of cell surface NKp46 availability and the up-regulation of Helios transcript that lead to NK cell hyperactivity remains unclear.

Additional TF have been implicated in the final differentiation of NK cells. In addition to its role in the transition from NKP $->$ iNK cells, Ets-1 also regulates homeostasis of mature NK cells. In the absence of Ets-1, mature NK cells have an activated phenotype with enhanced Helios expression and a hyper-responsiveness to IL$15[\bullet 15]$. Runx3 is highly expressed throughout NK cell development and targets of Runx3 include NKp46 and possibly CD122 and members of the Ly49 family [51,52].

Blimp1 (encoded at Prdm1) acts as transcriptional repressor that regulates the terminal differentiation of $B$ and $T$ cells (reviewed in $[53,54]$ ). In NK cells, Blimp1 regulates the frequency of terminally differentiated $\mathrm{CD} 27-\mathrm{CD} 11 \mathrm{~b}^{+} \mathrm{NK}$ cells. Like Ets-1deficient NK cells, Blimp1-deficient NK cells are hyper-responsive to IL-15 stimulation. Blimp1-deficiency might also impact on NK trafficking as Blimp1 was shown to regulate chemokine receptor expression in T cells (reviewed in [54]). While Blimp1-knockdown in human $\mathrm{NK}$ cells resulted in increased IFN- $\gamma$ production, murine NK cells lacking Blimp1 do not show alterations in IFN- $\gamma$ production $[55,56]$. The reason for this speciesspecific difference is not known but could be related to the presence of Hobit (homolog of Blimp1 in T cells, Znf683) a related TF that is highly expressed in NKT cells [••57]. While Hobit is apparently not expressed in resting wild-type NK cells, its expression (upregulation?) in the absence Blimp1 could contribute to the attenuated phenotype of 
Blimp1-deficient NK cells. As such, Hobit might sustain IFN- $\gamma$ production and cytotoxicity in Prdm1\% NK cells.

\section{An extended model for NK cell and other ILC subset development}

We would like to propose a model that takes into account these different observations thus far discussed. It is now documented that CLP can give rise to B, T, NK and ILC2 in vivo; whether CLP are precursors for ILC3 subsets needs to be shown. In contrast, dedicated precursors for ILC subsets that are downstream of CLP are less clearly defined in adult mice. Ample evidence exists for the presence of a NKP that has NK lineage potential, but the existence of a 'common ILC precursor' (ILCp) that can subsequently give rise at the clonal level to ILC1, ILC2 and ILC3 subsets has been proposed [ $\bullet 8]$ but not clearly documented. Up-regulation of Id 2 in CLP would provide a mechanism to restrict CLP to the non-T, non-B cell fate and would be necessary for subsequent ILC subset differentiation (Figure 2). If such an ILCp exists, it would then undergo additional transcriptional changes to selectively differentiate towards individual ILC sublineages. Previous studies have identified Notch signals as important for ILC2 and lymphoid-tissue inducer (LTi, an ILC3 subset) cell generation [ $\bullet 58-\bullet \bullet 60]$ from multipotent lymphoid precursors. In contrast, NK cells do not apparently require Notch signals $[\bullet 48,61]$ to develop from CLP. Thus Notch signals could provide an early mechanism to initiate ILC subset differentiation from ILCp. In this model, ILC2 and ILC3 (at least the LTi cell subset) would more closely resemble T cells in their requirements for Notch. Potential downstream targets for Notch in early T cells include Tcf1, Bcl11b and Gata3; the latter could have a dominant role in the initiation of ILC2 specification and its completion via ROR $\alpha$. A similar mechanism could be operative in the generation of ROR $\gamma \mathrm{t}^{+}$ILC3 subsets. Still, sustained Notch signaling appears detrimental for ILC3 homeostasis as it favors T cell development at the expense of ILC3 precursors $[\bullet \bullet 60]$.

In contrast, these same factors (Notch, Gata3, ROR $\alpha, \mathrm{ROR} \gamma \mathrm{t}$ ) have little or no apparent impact on 'mainstream' NK cell development in the bone marrow. In contrast, two TF have critical roles at the earliest stages: Nfil3 and T-bet. While these two TF have no obvious ability to interact physically or functionally, their coincident expression and critical roles in the generation of iNK from NKP are clearly demonstrated. Up-regulation of T-bet and Nfil3 in CLP and/or ILCp are likely to be critical in the early stages of 
commitment to the ILC1 lineage as NKP are generated. What mechanisms might control Nfil3 and/or T-bet expression? Although clear answers are not yet available, there are several hypotheses. First, as yet unidentified TF(s) may link Id2 expression (and loss of E-box activity) with up-regulation of Nfil3 or T-bet. These might be identified through comparison of TF profiles between CLP and pre-NKP. Alternatively, the absence of Notch signaling in ILC precursors may be associated with default expression of Nfil3 or T-bet that can then be stably reinforced by extrinsic signals (cytokines).

In the not so distant past, the transcriptional map of NK cell development consisted of a straight line between the hematopoietic stem cell and the mature NK cell with no defining directional markers. We now have a detailed phenotypic model for the emergence of mature NK cells from hematopoietic precursors that proposes a step-bystep process of commitment to the NK lineage, education to self MHC, and maturation and acquisition of NK cell effector functions. Several key TF that guide this process have been revealed and provide a framework for a better understanding of NK cell differentiation in particular, and of ILC development in general.

\section{Acknowledgements}

This work was supported by institutional support grants from the Institut Pasteur, Inserm, Ligue National Contre le Cancer and the ANR through the Program 'Blanc' (Gut_ILC). 


\section{Figure Legends}

\section{Figure 1. Stages of NK cell development from CLP in the mouse}

In the mouse, refined NK cell precursors (rNKP) represent the earliest precursor committed to the NK lineage (stage 1). Precursor potential of pre-NKP for other ILC lineage remains to be verified. The iNK and mNK nomenclature is based on absence or presence of DX5 expression. Current knowledge allows for their further subdivision according to the markers indicated on the left as indicated by the "stages". Of note, rNKP comprise $\mathrm{CD} 127^{+}$and $\mathrm{CD} 127^{-}$cells. It should also be noted that only a fraction of iNK and mNK cells express CD94 in adult mice. Similarly, any given Ly49 is expressed at a characteristic frequency in mature NK cells, which is dependent on the genetic background ("Ly49 repertoire").

Figure 2. Schematic view of NK development in the bone marrow and liver and comparison with ILC2 and ILC3 development in the mouse

Transcription factors and their potential targets are indicated. DX5- and DX5+ NK cell subsets are present in hepatic tissue, although their origin remains a matter of debate (dotted arrows). The impact of Nfil3/E4bp4 on iNK cells has been documented, but the potential effects of this TF on NKP is unclear and should be revisited. Runx3 and Gata3 control of Eomes expression has been demonstrated in T cells but their role in NK cells is still speculative. A similar comment applies to the putative role of Notch for Gata3 induction in ILC2. 


\section{References and recommended reading}

1. Di Santo JP: Natural killer cell developmental pathways: a question of balance. Annu Rev Immunol 2006, 24:257-86.

2. Blom B, Spits H: Development of human lymphoid cells. Annu. Rev. Immunol. 2006, 24:287-320.

3. Huntington ND, Vosshenrich CAJ, Di Santo JP: Developmental pathways that generate natural-killer-cell diversity in mice and humans. Nat. Rev. Immunol 2007, 7:703-714.

4. Cherrier M, Ohnmacht C, Cording S, Eberl G: Development and function of intestinal innate lymphoid cells. Curr. Opin. Immunol. 2012, 24:277-283.

5. Colonna M: Interleukin-22-producing natural killer cells and lymphoid tissue inducer-like cells in mucosal immunity. Immunity 2009, 31:15-23.

6. Koyasu S, Moro K, Tanabe M, Takeuchi T: Natural helper cells: a new player in the innate immune response against helminth infection. Adv. Immunol. 2010, 108:21-44.

7. Spits H, Di Santo JP: The expanding family of innate lymphoid cells: regulators and effectors of immunity and tissue remodeling. Nat. Immunol. 2011, 12:21-27.

$\bullet$. Spits H, Artis D, Colonna M, Diefenbach A, Di Santo JP, Eberl G, Koyasu S, Locksley RM, McKenzie ANJ, Mebius RE, et al.: Innate lymphoid cells - a proposal for uniform nomenclature. Nat. Rev. Immunol. 2013, 13:145-149.

A proposal for a standardized nomenclature for ILC that groups subsets based on cytokine production profiles and transcription factor expression.

9. Kondo M, Weissman IL, Akashi K: Identification of clonogenic common lymphoid progenitors in mouse bone marrow. Cell 1997, 91:661-72.

$\bullet$ 10. Wong SH, Walker JA, Jolin HE, Drynan LF, Hams E, Camelo A, Barlow JL, Neill DR, Panova V, Koch $U$, et al.: Transcription factor ROR $\alpha$ is critical for nuocyte development. Nat. Immunol. 2012, 13:229-236.

See also $\bullet \bullet 17$

11. Yang Q, Saenz SA, Zlotoff DA, Artis D, Bhandoola A: Cutting edge: Natural helper cells derive from lymphoid progenitors. J. Immunol. 2011, 187:5505-5509.

12. Rosmaraki EE, Douagi I, Roth C, Colucci F, Cumano A, Di Santo JP: Identification of committed NK cell progenitors in adult murine bone marrow. Eur J Immunol 2001, 31:1900-9.

$\bullet$ 13. Fathman JW, Bhattacharya D, Inlay MA, Seita J, Karsunky H, Weissman IL:

Identification of the earliest natural killer cell-committed progenitor in murine bone marrow. Blood 2011, 118:5439-5447.

See also $\bullet \bullet 16$ 
14. Vosshenrich CAJ, Ranson T, Samson SI, Corcuff E, Colucci F, Rosmaraki EE, Di Santo JP: Roles for common cytokine receptor gamma-chain-dependent cytokines in the generation, differentiation, and maturation of $\mathrm{NK}$ cell precursors and peripheral NK cells in vivo. $J$. Immunol 2005, 174:1213-1221.

$\bullet$ 15. Ramirez K, Chandler KJ, Spaulding C, Zandi S, Sigvardsson M, Graves BJ, Kee BL: Gene deregulation and chronic activation in natural killer cells deficient in the transcription factor ETS1. Immunity 2012, 36:921-932.

Identification of an essential role for Ets1 in the development of NK precursors with possible regulation through control of Id 2 expression

••16. Carotta S, Pang SHM, Nutt SL, Belz GT: Identification of the earliest NK-cell precursor in the mouse BM. Blood 2011, 117:5449-5452.

With $\bullet 13$ identification of earliest committed NK cell progenitors using a novel phenotypic cluster and Id 2 reporter expression

$\bullet$ 17. Halim TYF, MacLaren A, Romanish MT, Gold MJ, McNagny KM, Takei F:

Retinoic-acid-receptor-related orphan nuclear receptor alpha is required for natural helper cell development and allergic inflammation. Immunity 2012, 37:463-474.

With $\bullet 10$ identification of RORa as an essential factor in the development of ILC2

18. Cedar H, Bergman Y: Epigenetics of haematopoietic cell development. Nat. Rev. Immunol. 2011, 11:478-488.

19. Heinz S, Glass CK: Roles of lineage-determining transcription factors in establishing open chromatin: lessons from high-throughput studies. Curr. Top. Microbiol. Immunol. 2012, 356:1-15.

20. Cui K, Zang C, Roh T-Y, Schones DE, Childs RW, Peng W, Zhao K: Chromatin signatures in multipotent human hematopoietic stem cells indicate the fate of bivalent genes during differentiation. Cell Stem Cell 2009, 4:80-93.

21. Weishaupt H, Sigvardsson M, Attema JL: Epigenetic chromatin states uniquely define the developmental plasticity of murine hematopoietic stem cells. Blood 2010, 115:247.

- 22. Zhang JA, Mortazavi A, Williams BA, Wold BJ, Rothenberg EV: Dynamic transformations of genome-wide epigenetic marking and transcriptional control establish T cell identity. Cell 2012, 149:467-482.

Identification of critical binding sites for Gata3 in early $\mathrm{T}$ cell progenitors that may control $\mathrm{T}$ lineage specification

23. Yokota Y, Mansouri A, Mori S, Sugawara S, Adachi S, Nishikawa S, Gruss P: Development of peripheral lymphoid organs and natural killer cells depends on the helix-loop-helix inhibitor Id2. Nature 1999, 397:702-6.

24. Boos MD, Yokota Y, Eberl G, Kee BL: Mature natural killer cell and lymphoid tissue-inducing cell development requires Id2-mediated suppression of $E$ protein activity. J. Exp. Med. 2007, 204:1119-1130. 
25. Aliahmad P, De la Torre B, Kaye J: Shared dependence on the DNA-binding factor TOX for the development of lymphoid tissue-inducer cell and NK cell lineages. Nat. Immunol. 2010, 11:945-952.

26. Wang JH, Nichogiannopoulou A, Wu L, Sun L, Sharpe AH, Bigby M, Georgopoulos $\mathrm{K}$ : Selective defects in the development of the fetal and adult lymphoid system in mice with an Ikaros null mutation. Immunity 1996, 5:537-49.

27. Zeng H, Yücel R, Kosan C, Klein-Hitpass L, Möröy T: Transcription factor Gfi1 regulates self-renewal and engraftment of hematopoietic stem cells. $E M B O J$. 2004, 23:4116-4125.

28. Dias S, Månsson R, Gurbuxani S, Sigvardsson M, Kee BL: E2A proteins promote development of lymphoid-primed multipotent progenitors. Immunity 2008, 29:217-227.

29. Grenningloh R, Tai T-S, Frahm N, Hongo TC, Chicoine AT, Brander C, Kaufmann DE, Ho I-C: Ets-1 Maintains IL-7 Receptor Expression in Peripheral T Cells. J Immunol 2011, 186:969-976.

30. Cowell IG, Skinner A, Hurst HC: Transcriptional repression by a novel member of the bZIP family of transcription factors. Mol. Cell. Biol. 1992, 12:3070-3077.

31. Male V, Nisoli I, Gascoyne DM, Brady HJM: E4BP4: an unexpected player in the immune response. Trends Immunol. 2012, 33:98-102.

• 32. Gascoyne DM, Long E, Veiga-Fernandes H, De Boer J, Williams O, Seddon B, Coles M, Kioussis D, Brady HJM: The basic leucine zipper transcription factor E4BP4 is essential for natural killer cell development. Nat. Immunol 2009, 10:1118-1124.

See also $\bullet \cdot 33$

••33. Kamizono S, Duncan GS, Seidel MG, Morimoto A, Hamada K, Grosveld G, Akashi $\mathrm{K}$, Lind EF, Haight JP, Ohashi PS, et al.: Nfil3/E4bp4 is required for the development and maturation of NK cells in vivo. J. Exp. Med 2009, 206:2977-2986.

With $\bullet 32$ identification of critical role for Nfil3/E4bp4 in NK cell development

34. Kashiwada M, Levy DM, McKeag L, Murray K, Schröder AJ, Canfield SM, Traver G, Rothman PB: IL-4-induced transcription factor NFIL3/E4BP4 controls IgE class switching. Proc. Natl. Acad. Sci. U.S.A 2010, 107:821-826.

35. Santo JPD: A defining factor for natural killer cell development. Nature Immunology 2009, 10:1051-1052.

36. Townsend MJ, Weinmann AS, Matsuda JL, Salomon R, Farnham PJ, Biron CA, Gapin L, Glimcher LH: T-bet regulates the terminal maturation and homeostasis of NK and Valpha14i NKT cells. Immunity 2004, 20:477-94.

37. Jenne CN, Enders A, Rivera R, Watson SR, Bankovich AJ, Pereira JP, Xu Y, Roots CM, Beilke JN, Banerjee A, et al.: T-bet-dependent S1P5 expression in NK cells promotes egress from lymph nodes and bone marrow. J. Exp. Med. 2009, 206:2469-2481.

38. Naiche LA, Harrelson Z, Kelly RG, Papaioannou VE: T-box genes in vertebrate development. Annu. Rev. Genet. 2005, 39:219-239. 
39. Intlekofer AM, Takemoto N, Wherry EJ, Longworth SA, Northrup JT, Palanivel VR, Mullen AC, Gasink CR, Kaech SM, Miller JD, et al.: Effector and memory CD8+ T cell fate coupled by T-bet and eomesodermin. Nat. Immunol. 2005, 6:1236-1244.

40. Cruz-Guilloty F, Pipkin ME, Djuretic IM, Levanon D, Lotem J, Lichtenheld MG, Groner Y, Rao A: Runx3 and T-box proteins cooperate to establish the transcriptional program of effector CTLs. J. Exp. Med. 2009, 206:51-59.

$\bullet$ •41. Gordon SM, Chaix J, Rupp LJ, Wu J, Madera S, Sun JC, Lindsten T, Reiner SL: The transcription factors T-bet and Eomes control key checkpoints of natural killer cell maturation. Immunity 2012, 36:55-67.

Identification of specific and redundant roles for T-bet and Eomes in the development of NK cell precursors and mature NK cells

42. Takeda K, Cretney E, Hayakawa Y, Ota T, Akiba H, Ogasawara K, Yagita H, Kinoshita K, Okumura K, Smyth MJ: TRAIL identifies immature natural killer cells in newborn mice and adult mouse liver. Blood 2005, 105:2082-9.

43. Samson SI, Richard O, Tavian M, Ranson T, Vosshenrich CAJ, Colucci F, Buer J, Grosveld F, Godin I, Di Santo JP: GATA-3 promotes maturation, IFN-gamma production, and liver-specific homing of NK cells. Immunity 2003, 19:701-711.

44. Vosshenrich CAJ, García-Ojeda ME, Samson-Villéger SI, Pasqualetto V, Enault L, Richard-Le Goff O, Corcuff E, Guy-Grand D, Rocha B, Cumano A, et al.: A thymic pathway of mouse natural killer cell development characterized by expression of GATA3 and CD127. Nat. Immunol 2006, 7:1217-1224.

45. Rothenberg EV: Transcriptional drivers of the T-cell lineage program. Curr. Opin. Immunol. 2012, 24:132-138.

• 46. Hoyler T, Klose CSN, Souabni A, Turqueti-Neves A, Pfeifer D, Rawlins EL, Voehringer D, Busslinger M, Diefenbach A: The Transcription Factor GATA-3 Controls Cell Fate and Maintenance of Type 2 Innate Lymphoid Cells. Immunity 2012, 37:634 648.

See also $\bullet 47$

• 47. Mjösberg J, Bernink J, Golebski K, Karrich JJ, Peters CP, Blom B, Te Velde AA, Fokkens WJ, Van Drunen CM, Spits H: The Transcription Factor GATA3 Is Essential for the Function of Human Type 2 Innate Lymphoid Cells. Immunity 2012, 37:649-659.

With $\bullet 46$ identification of Gata3 signaling in the development of ILC2

-48. Ribeiro VSG, Hasan M, Wilson A, Boucontet L, Pereira P, Lesjean-Pottier S, SatohTakayama N, Di Santo JP, Vosshenrich CAJ: Cutting edge: Thymic NK cells develop independently from T cell precursors. J. Immunol 2010, 185:4993-4997.

Identification that thymic NK cells have a unique intrathymic origin

49. Klein Wolterink RGJ, García-Ojeda ME, Vosshenrich CAJ, Hendriks RW, Di Santo JP: The intrathymic crossroads of $\mathbf{T}$ and NK cell differentiation. Immunol. Rev 2010, 238:126-137. 
50. Narni-Mancinelli E, Jaeger BN, Bernat C, Fenis A, Kung S, De Gassart A, Mahmood S, Gut M, Heath SC, Estellé J, et al.: Tuning of natural killer cell reactivity by NKp46 and Helios calibrates T cell responses. Science 2012, 335:344-348.

51. Ohno S, Sato T, Kohu K, Takeda K, Okumura K, Satake M, Habu S: Runx proteins are involved in regulation of CD122, Ly49 family and IFN-gamma expression during NK cell differentiation. Int. Immunol. 2008, 20:71-79.

52. Lai CB, Mager DL: Role of runt-related transcription factor 3 (RUNX3) in transcription regulation of natural cytotoxicity receptor 1 (NCR1/NKp46), an activating natural killer (NK) cell receptor. J. Biol. Chem. 2012, 287:7324-7334.

53. Nutt SL, Taubenheim N, Hasbold J, Corcoran LM, Hodgkin PD: The genetic network controlling plasma cell differentiation. Semin. Immunol. 2011, 23:341-349.

54. Xin A, Nutt SL, Belz GT, Kallies A: Blimp1: driving terminal differentiation to a T. Adv. Exp. Med. Biol. 2011, 780:85-100.

55. Smith MA, Maurin M, Cho HI, Becknell B, Freud AG, Yu J, Wei S, Djeu J, Celis E, Caligiuri MA, et al.: PRDM1/Blimp-1 controls effector cytokine production in human NK cells. J. Immunol. 2010, 185:6058-6067.

56. Kallies A, Carotta S, Huntington ND, Bernard NJ, Tarlinton DM, Smyth MJ, Nutt SL: A role for Blimp1 in the transcriptional network controlling natural killer cell maturation. Blood 2011, 117:1869-1879.

••57. Van Gisbergen KPJM, Kragten NAM, Hertoghs KML, Wensveen FM, Jonjic S, Hamann J, Nolte MA, Van Lier RAW: Mouse Hobit is a homolog of the transcriptional repressor Blimp-1 that regulates NKT cell effector differentiation. Nat. Immunol. 2012, 13:864-871.

Identification of a Blimp-1 homologue that is highly expressed in innate lymphocytes

••58. Lee JS, Cella M, McDonald KG, Garlanda C, Kennedy GD, Nukaya M, Mantovani A, Kopan R, Bradfield CA, Newberry RD, et al.: AHR drives the development of gut ILC22 cells and postnatal lymphoid tissues via pathways dependent on and independent of Notch. Nat. Immunol. 2012, 13:144-151.

See also $\bullet \bullet 59, \bullet \bullet 60$

-•59. Possot C, Schmutz S, Chea S, Boucontet L, Louise A, Cumano A, Golub R: Notch signaling is necessary for adult, but not fetal, development of $\operatorname{ROR} \gamma \mathrm{t}(+)$ innate lymphoid cells. Nat. Immunol. 2011, 12:949-958.

See also $\bullet \cdot 58, \bullet \bullet 60$

- 60. Cherrier M, Sawa S, Eberl G: Notch, Id2, and ROR $\gamma$ t sequentially orchestrate the fetal development of lymphoid tissue inducer cells. J. Exp. Med. 2012, 209:729-740.

With $\bullet 58, \bullet 59$ identification of Notch signaling in the development of ILC3 subsets

61. Radtke F, Wilson A, Stark G, Bauer M, Van Meerwijk J, MacDonald HR, Aguet M: Deficient $T$ cell fate specification in mice with an induced inactivation of Notch1. Immunity 1999, 10:547-58. 


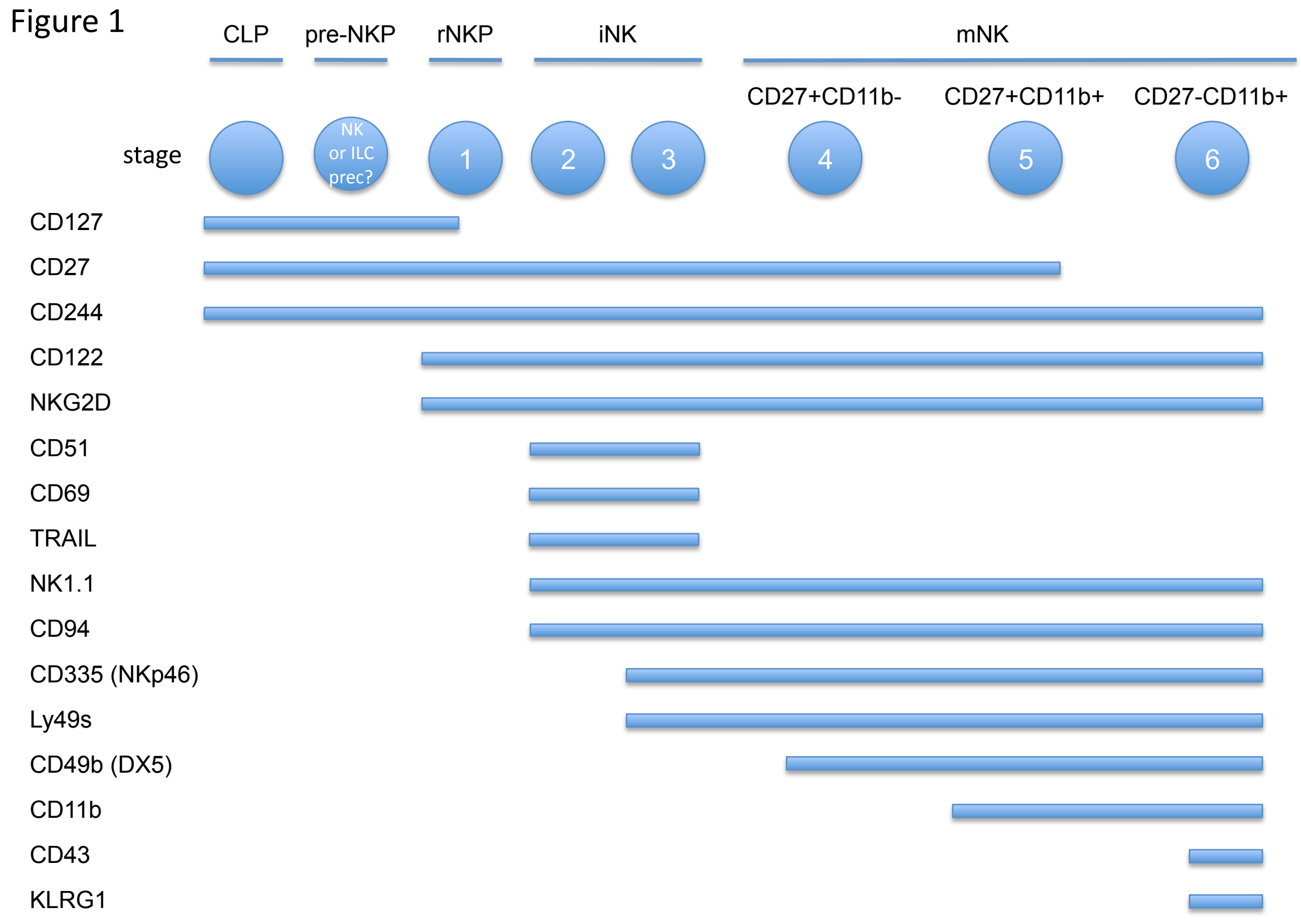


Figure 2

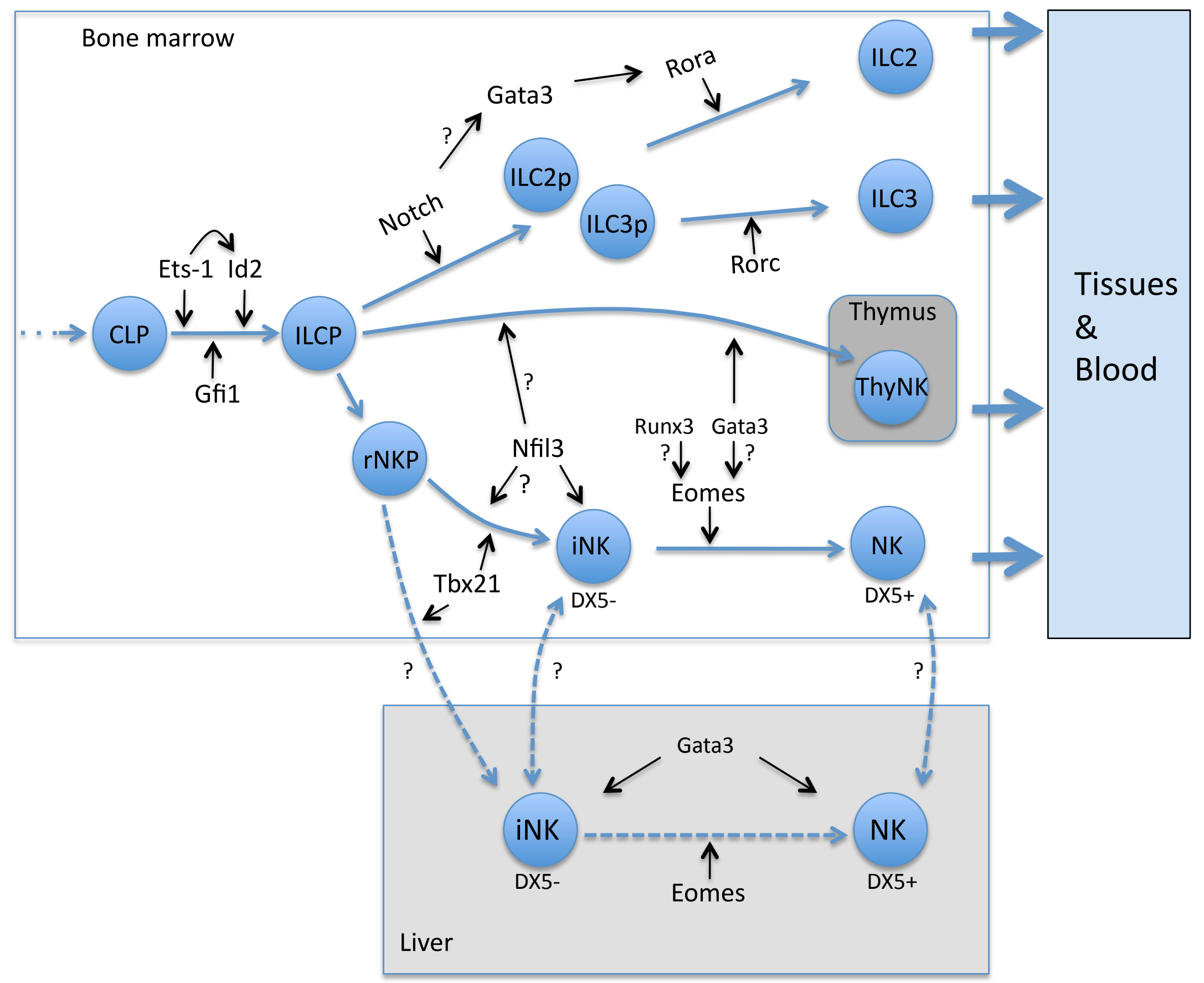

